\title{
Power Flow Control of Iraqi International Super Grid with Two- Terminal HVDC Techniques Using PSS/E
}

\author{
Yasar N. Lafta ${ }^{1 *}$, Nadheer A. Shalash ${ }^{2}$, Yaser N. Abd ${ }^{3}$ and Ali A. Al- Lami ${ }^{4}$ \\ ${ }^{I}$ Mechatronics Engineering Department, Al-Khawarizmi college of Engineering, \\ University of Baghdad, Baghdad, Iraq \\ ${ }^{2}$ Faculty of Engineering of Electrical power techniques, Al-Maamoon University \\ College, Baghdad, Iraq \\ ${ }^{3}$ Planning and studies office, Ministry of Electricity, Baghdad, Iraq \\ ${ }^{4}$ Planning and studies office, Ministry of Electricity, Baghdad, Iraq \\ 1yasar@kecbu.uobaghdad.edu.iq, ${ }^{2}$ eng_n_a_msc@yahoo.com, \\ 3yasernadhum@yahoo.com, ${ }^{4}$ allamimalla@gmail.com
}

\begin{abstract}
The use of HVDC in transmission system is an important technique to improve AC power system performance. PSS/E software is a conventional package used to simulate power system, from which power flow study that involves numerical analysis of power system displays convergence progress. Short circuit activity enables engineer to decide the proper location of HVDC links in order to obtain the best minimization of short circuit currents overall buses in the grid. In this paper PSS/E is used for modelling monopolar and bipolar DC lines in an effective region of Iraqi super grid, in second hand, makes comparative studies to test location for short circuit levels (SCLs) between actual AC and $A C / D C$ case study as part of Iraqi national grid. The finding of this article appears that the addition of DC link leads to power improvement, with the fact that SCL is reduced with bipolar line installation rather than monopolar line.
\end{abstract}

Keywords: Baghdad governorate; optimized converters; ac system coupling; ac line replacement

\section{Introduction}

Power electronic techniques are used in power system applications presenting excellent performance. Today, the most power devices employed in HVDC are thyristors, and isolated gate bipolar transistor (IGBT) [1].

Conversion in classic HVDC is done by thyristors, whereas conversion in voltage source converters (VSC) is done by transistors (IGBT's).

HVDC transmission that is built in 1954 was the first marketable use for mercury valves linking Gotland and the Swedish mainland [2]. After that line commutated converters (LCC) was the most HVDC technique that is in use [3,4].

HVDC link controls AC network power flow. Thus load flow can be optimized effectively by HVDC link reducing losses, increasing capacity and improving stability [5]. Control approach is to satisfy dispatch mechanism during normal operation, and to implement satisfactory operations during AC contingencies [6].

DC grid technology is an economic choice having better resolution when compared with AC transmission network, different voltages of DC lines are interconnected using DC/DC converter constructing DC grid [7]. DC grid enriches system flexibility, reliability, and improves redundancy by allocation resources which decrease power losses

Received (October 24, 2017), Review Result (January 18, 2018), Accepted (January 29, 2018)

* Corresponding Author 
[8]. The general DC links advantage is that short-circuit currents of AC system will not increase.

HVDC is preferred more than 3phase AC transmission system for the reasons that HVDC constructing cost is less; it doesn't need for synchronization between two AC systems, and fast power flow control [9], besides that HVDC limits short circuit currents.

Technology development of power system makes it essential to employ PSS/E due to its ability of updating; in both numerical analysis methods and component models [10].

PSS/E package studies performance of transmission and generation systems in steadystate and dynamic conditions. Power Flow activity requires an iterative method to solve both network condition and boundary conditions [11]. Double AC contingencies analysis of power flow and transient stability can be determined on the system verifying apparatus short circuit capability [12].

HVDC can be modelled in power flow programs and transient stability software such as PSS/E. This software executes IEC 60909 Standard to calculate short-circuit currents. Maximum fault level occurs at generation busbars, due to massive effect on supplying grid.

Typically, 3-phase fault causes the highest current thus it is suitable to execute shortcircuit activity for Iraqi $400 \mathrm{KV}$ grid with three phase fault which reveals the most high short circuit currents.

\section{DC System Concepts}

AC load flow provides voltages of ac buses connected to dc system. Line commutated converters are part of all two-terminal dc lines; "Pole control is the core of HVDC control and activates the appropriate controller of the rectifier and inverter station according to the state of AC/DC systems. Then it produces the firing angle for both rectifier and inverter stations" [9].

Rectifier controls the dc current to attain desired power as in eqn. (1):

$I_{d}=\frac{\text { Power }_{\text {desired }}}{\text { Vdc Scheduled }}$

The inverter must typically operates at $(\gamma)$ higher than minimum to control ac voltage. As angle limits are assumed, power flow solution logic adjust the bridge control angle $(\alpha)$ or $(\gamma)$, and transformer tap position to control dc voltage and current [13].

The converter DC voltage is given by expressions in terms of rectifier firing delay angle and transmission DC current as in eqn. (2):

$V_{d r}=N_{r}\left[\frac{3 \sqrt{2}}{\pi} \cos \left(\alpha_{r}\right) E_{a r}-\frac{3}{\pi} X_{c r} I_{d}-2 R_{r} I_{d}\right]$

Where:

$\mathrm{V}_{\mathrm{dr}}=$ Rectifier DC line voltage;

$\mathrm{N}_{\mathrm{r}}=$ Number of rectifier bridges in series;

$\alpha_{r}=$ Rectifier delay angle;

$\mathrm{E}_{\mathrm{ar}}=$ Converter Transformer secondary open-circuit voltage;

$\mathrm{I}_{\mathrm{d}}=$ Transmission DC current;

$\mathrm{R}_{\mathrm{r}}=$ Rectifier transformer secondary commutating resistance in ohms per bridge; and

$\mathrm{X}_{\mathrm{cr}}=$ Rectifier transformer secondary commutating reactance in ohms per bridge.

Assuming zero-commuting drop initially then:

$\frac{V_{d r}}{N_{r}}=\frac{3 \sqrt{2}}{\pi} \cos (\alpha) E_{\text {ar }}$

In other side Inverter DC line voltage is given by eqn. (3): 
$V_{d i}=N_{i}\left[\frac{3 \sqrt{2}}{\pi} \cos (\gamma) E_{a i}-\frac{3}{\pi} I_{d} X_{c i}+2 I_{d} R_{i}\right]$

Where:

$\mathrm{V}_{\mathrm{di}}=$ Inverter DC line voltage;

$\mathrm{N}_{\mathrm{i}}=$ Number of inverter bridges in series;

$\gamma=$ inverter margin angle.

$\mathrm{E}_{\mathrm{ai}}=$ Converter Transformer secondary open-circuit voltage;

$\mathrm{R}_{\mathrm{i}}=$ Inverter transformer secondary commutating resistance in ohms per bridge; and

$\mathrm{X}_{\mathrm{ci}}=$ Inverter transformer secondary commutating reactance in ohms per bridge.

$\mathrm{AC}$ currents in rectifier or inverter transformer side are given in eqn. (4):

$I_{a r}=I_{a i}=\frac{\sqrt{6}}{\pi} I_{d} N_{r}$

Where $\mathrm{I}_{\mathrm{a}(\mathrm{r}, \mathrm{i})}=\mathrm{AC}$ currents in rectifier or inverter transformer side.

Tap change controller (TCC) maintains rectifier delay angle $\alpha$ within a definite range, usually $\left(12^{\circ}-15^{\circ}\right)$. If $\alpha$ margins are violated, then TCC is activated and AC voltage is varied accordingly. TCC at inverter side maintains DC voltage equal to the scheduled value. For safe commutation extinction angle control maintained constant, and DC voltage variation is controlled by tap changer [1].

Voltages of the converters transformer tap $(\mathrm{Vdc})$ is equal to the reference voltage which is assumed; then tap can be determined for every converter transformer. If these taps are in the range of limits, then ac-dc solution can be obtained. However, violation of upper and lower limits of any converter transformer tap causes $\mathrm{Vdc}$ to be rescheduled with a repeated procedure.

If the HVDC is planned to replace the present AC line, then flow change in the line will be detected using the present data of the system, because the location data of the newly planned HVDC is the same as the replaced AC line [14].

Case study consists of two cases the first case models a monopole HVDC transmission line where current return path is through earth and the other case model a bi-pole HVDC line.

These cases are applied on Iraqi $400 \mathrm{KV}$ international grid. Three-phase symmetrical short-circuit activity identified the points with high fault level of that grid. Bipolar DC line is modeled in the most high fault level busbar whereas monopolar DC line is modeled in that busbar with fault level less than the highest fault level.

\section{Iraqi Super Grid Overview}

It is important to introduce an over view of the Iraqi international super grid (400 KV) which represents the case study.

The peak generation is $14500 \mathrm{MW}$, and peak demand $22052 \mathrm{MW}$ so the shortage is $7552 \mathrm{MW}$ according to the Iraqi power system load after 10/6/2017.

Electrical power system of Iraq is divided into three operational subsystems; from the control point of view; North, Middle, and South regions.

Beside Kurdistan region isolation, north region network is almost isolated because of ISIS violence which contains Mosul Dam, Baiji PS, and Baiji GPS, and Kirkuk GPS station is in service connected with middle region which contains Haditha Dam ;isolated because of ISIS destroy; Basmia GPS, Quids GPS, Kherat GPS, Dewaniya GPS, Kut PS, Musayab PS, and Musayab GPS, and south region contains Amara GPS, Nassirya PS, Rumela GPS, Hartha PS, Shat Al Basra GPS, Najibia GPS and Khor Al-Zubair GPS as shown in Figure 1 [15]. Note that isolation is represented with vertical black lines in that figure. 


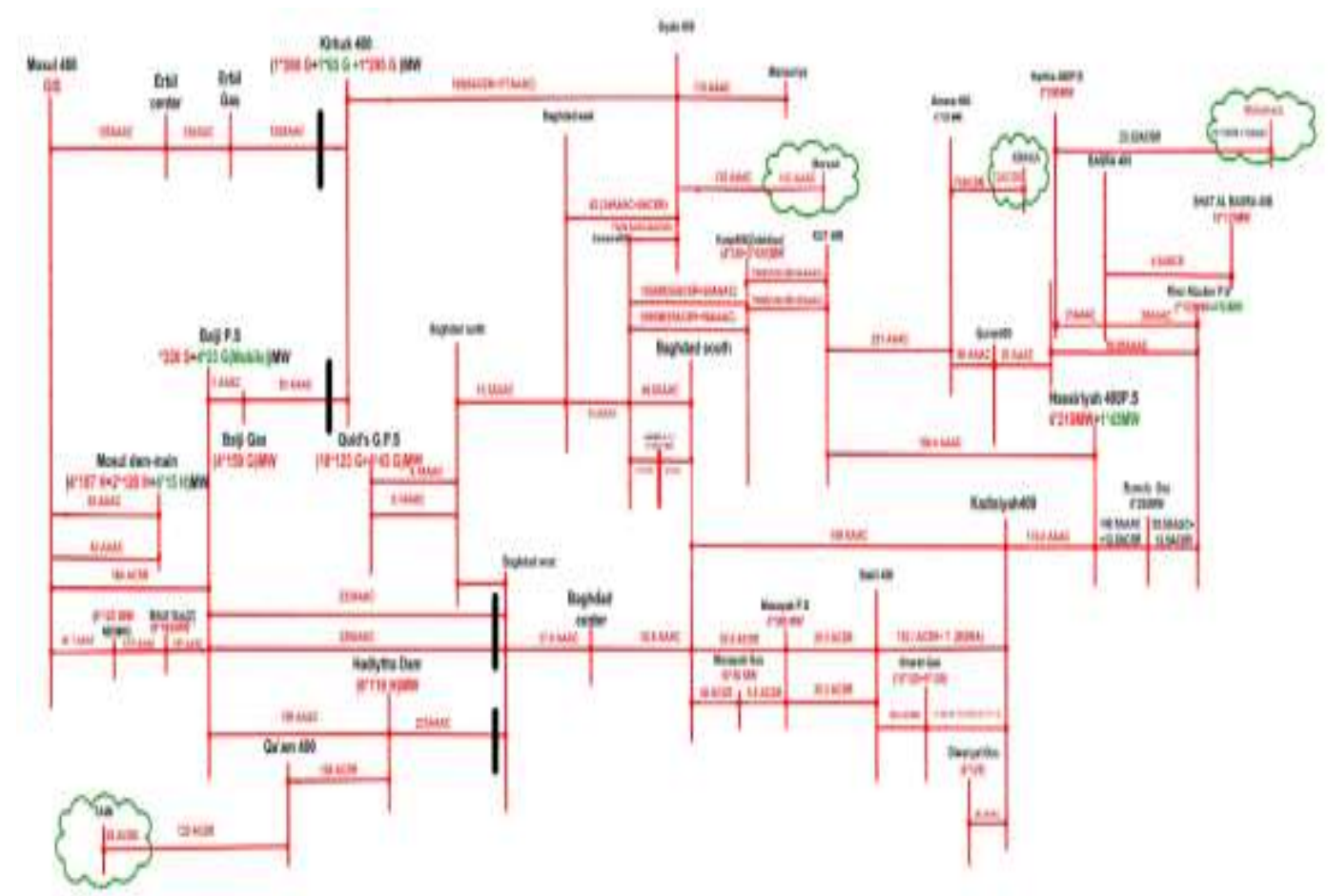

Figure 1. Iraq $400 \mathrm{KV}$ Grid

Fault level of large governorate like Baghdad is high. Mussyab thermal plant infeed the $400 \mathrm{kV}$ grid can deliver high fault infeed into Baghdad ring because the power plant local is close to Baghdad $400 \mathrm{kV}$ ring. Also Kut thermal plant (Zubidya) can bring high short circuit current for its high capacity and its intermediate distance from Baghdad ring.

This paper aims to limit fault level using HVDC link which prevent conveying short circuit currents into the $400 \mathrm{kV}$ network in Baghdad which in turn reduces short circuit currents at the $132 \mathrm{kV}$ network beneath.

Baghdad region $400 \mathrm{KV}$ electrical connections with Musayab and Kut (Zubidya) thermal plants are shown in Figure 2.

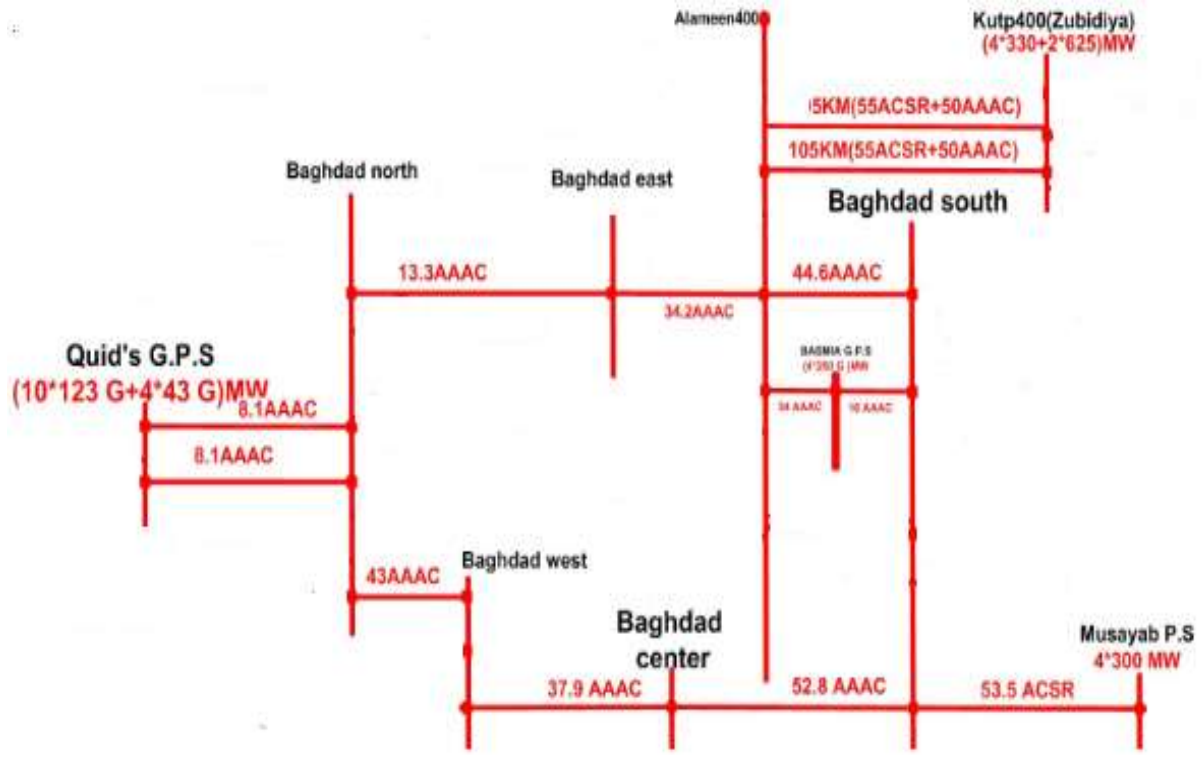

Figure 2. Baghdad Region $400 \mathrm{KV}$ Electrical Connections with Musayab and Kut 


\section{DC link in PSS/E}

PSS/E treats dc lines as considerable portion that share the power flow solution and their flow is documented in the output and report activities. Line commutated converters are part of every two-terminal dc line. Data of dc line is mostly specified in physical units (kilovolts, amperes, and ohms).

To start entering DC link data in PSSE click on two-terminal de line icon that is marked with red line in Figure 3 which shows lines of the two-terminal main screen display.

\subsection{Line Parameter}

Lines; marked with black line; main screen in Figure 3 represents Dc line parameters of the designed HVDC that must be identified with their values.

Desired data of main tabulated parameter is explained in the figure where control mode is either power or current.

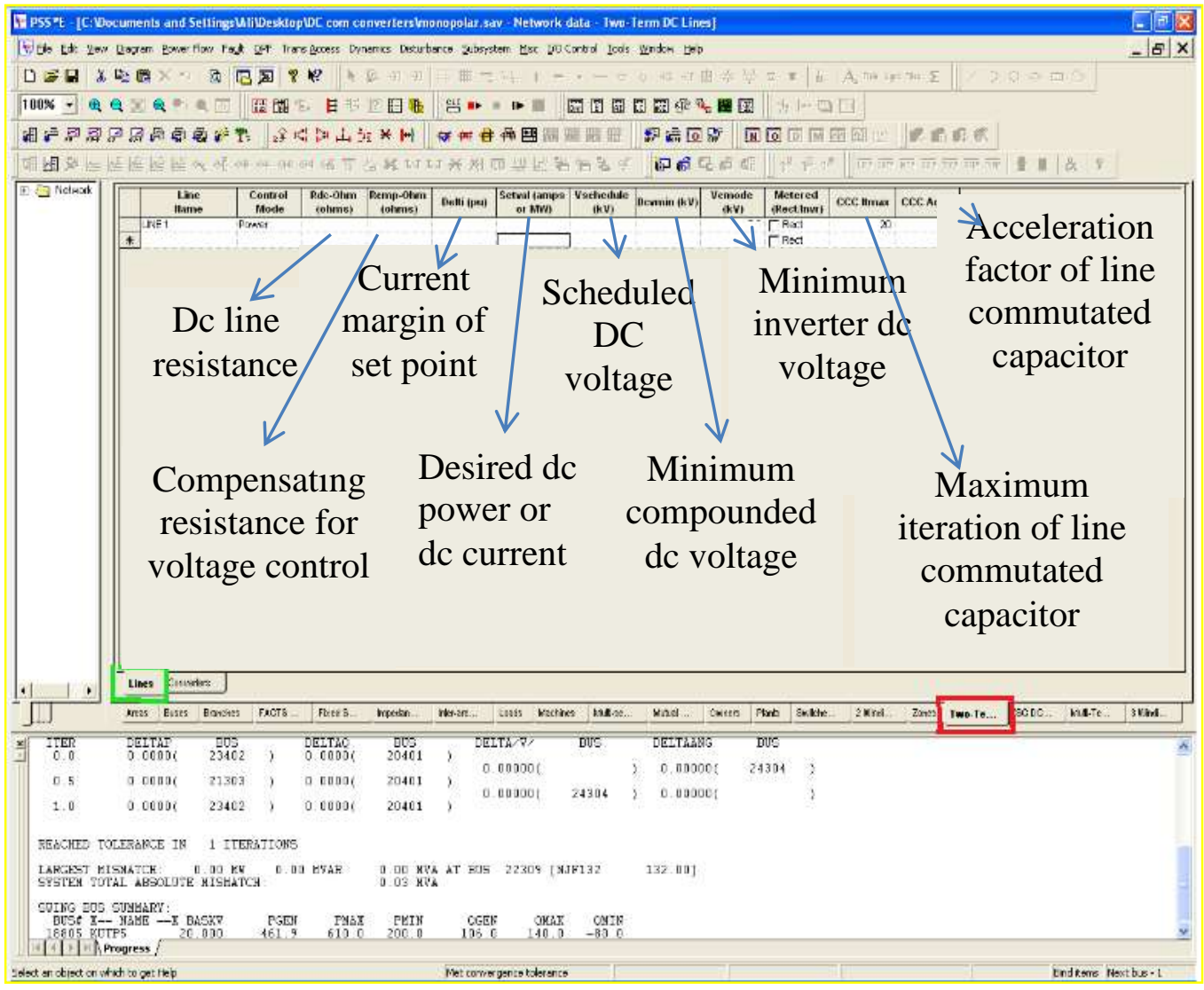

Figure 3. PSS/E Two-Terminal DC Line Parameters Identification

\subsection{Converter Parameter}

After selecting line raw click on converters icon; marked with yellow line in Figure 4; then converters main screen is displayed and tabulated converters parameters are clarified in Figure 4. 


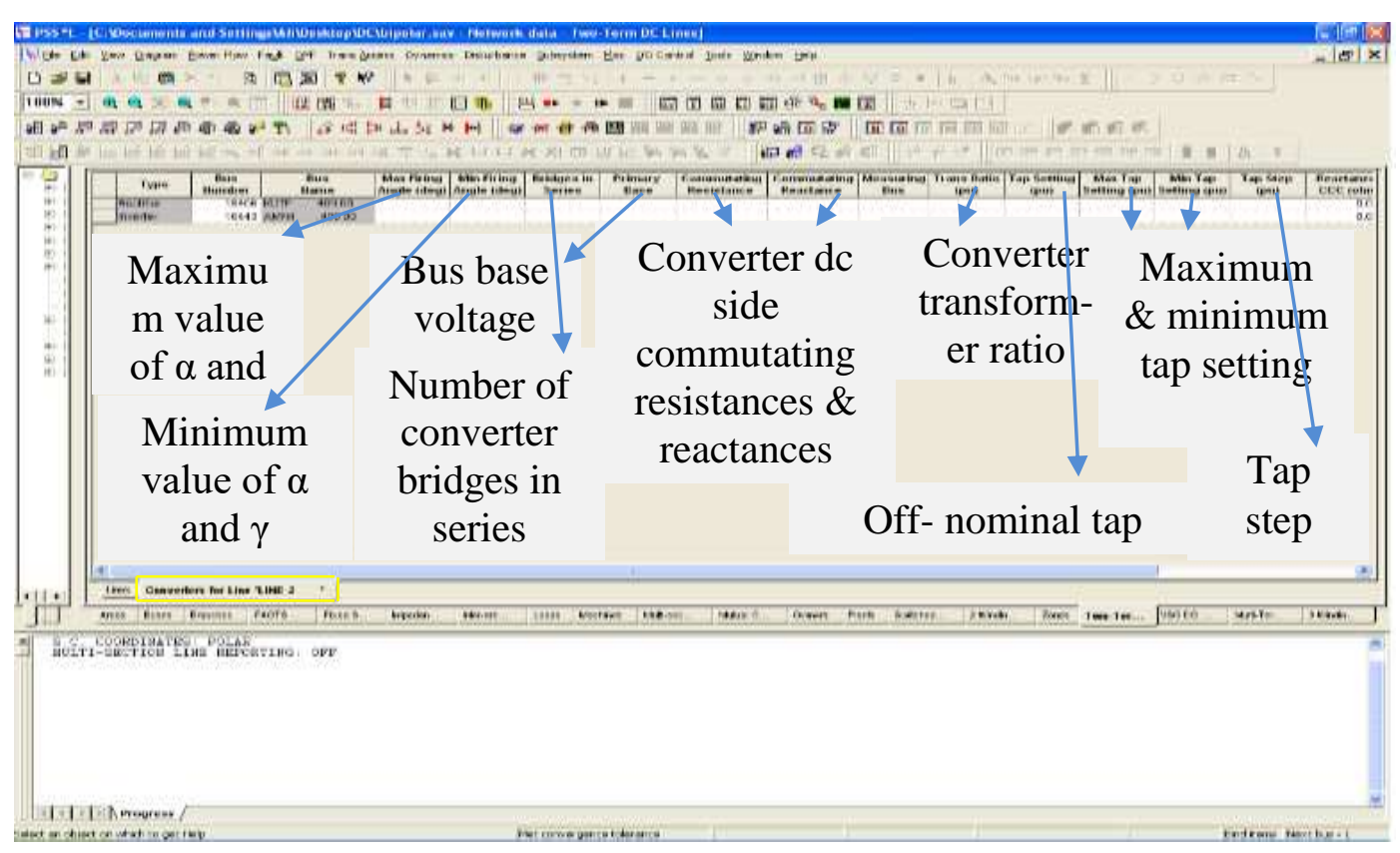

Figure 4. Main Screen of Converters and their Parameter Identification

\section{Case Study}

Three-phase symmetrical fault is executed using PSSE package to recognize high fault levels and their corresponding busbars. The results were as follows in Table 1.

Table 1. Highest Fault Levels

\begin{tabular}{|l|c|c|}
\hline busbar name and number & $\begin{array}{c}\text { Standard Power } \\
\text { Supply(MW) }\end{array}$ & $\begin{array}{c}\text { Fault level } \\
\text { (AMP) }\end{array}$ \\
\hline Alameen 16443 & - & 31964.9 \\
\hline Baghdad south 16419 & - & 30707.7 \\
\hline Kut PS 18406 & $4 * 330+2 * 625$ & 30517.8 \\
\hline Musayab PS 20401 & $4 * 300$ & 24920.2 \\
\hline
\end{tabular}

According to fault level results monopolar and bipolar converters are scheduled and optimized such that coordinating generation standards and loads on the AC network focusing on both $\mathrm{AC}$ and $\mathrm{DC}$ network limits.

\subsection{Monopole DC Network}

AC systems are coupled by converters i.e., busbar 20401 (Musayab PS) is connected to converter $\mathrm{C} 1$, also 16419 (Baghdad south) is connected to converter $\mathrm{C} 2$, and the DC line links the two AC systems with length $54 \mathrm{Km}$ and limit of $600 \mathrm{MW}$ as shown in Figure 5 where busbars out of Baghdad region are represented with circle shape and dotted ac transmission lines means isolation. 


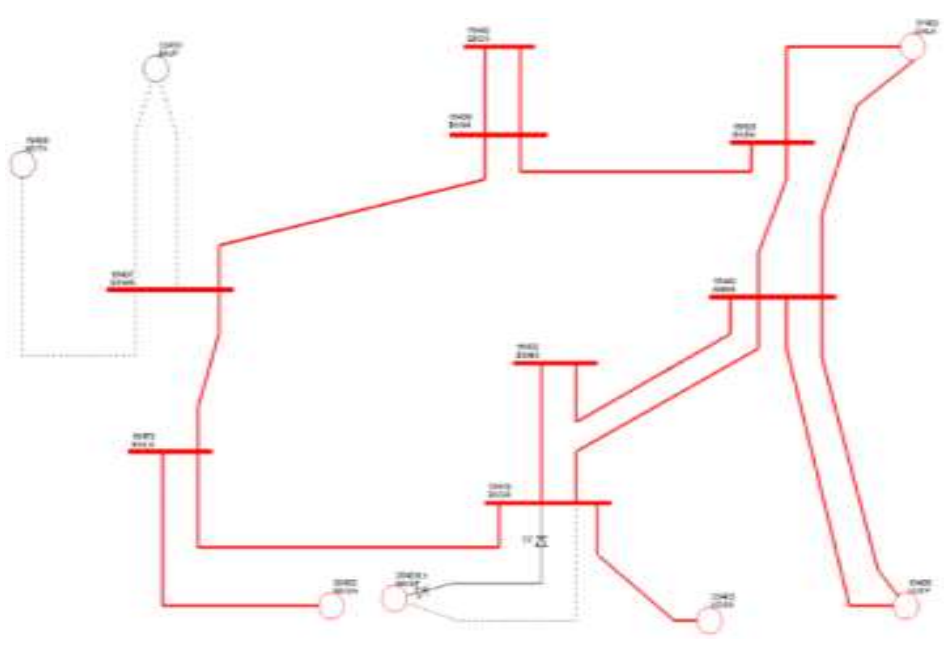

Figure 5. Monopole Connection with Baghdad Ring

Steady state monopolar DC line parameters are shown in Table 2, while converter parameters are shown in Table 3.

Table 2. DC Line Parameters Value of Monopole Model

\begin{tabular}{|c|c|}
\hline Parameter & Value \\
\hline Line Name & \\
\hline Control Mode & \\
\hline Rdc (Ohm) & \\
\hline Rcmp (Ohm) & \\
\hline Delti(per unit) & \\
\hline Setval( Mega Watt) & \\
\hline Vschedule(Kilo volt) & \\
\hline Dcvmin (Kilo volt) & \\
\hline Vcmode(Kilo volt) & \\
\hline CCC Itmax & \\
\hline CCC Accel & \\
\hline
\end{tabular}

Table 3. Converter Parameters Value of Monopole Model

\begin{tabular}{|c|c|c|}
\hline Parameter & $\begin{array}{c}\text { Rectifier } \\
\text { Value }\end{array}$ & $\begin{array}{c}\text { Inverter } \\
\text { value }\end{array}$ \\
\hline \multicolumn{3}{|l|}{ Bus Number } \\
\hline \multicolumn{3}{|l|}{ Bus Name } \\
\hline \multicolumn{3}{|l|}{ Max Firing angle $\left({ }^{\circ}\right)$} \\
\hline \multicolumn{3}{|l|}{ Min Firing angle $\left({ }^{\circ}\right)$} \\
\hline \multicolumn{3}{|l|}{ Bridges in series } \\
\hline \multicolumn{3}{|l|}{ Primary Base (Kilo volt) } \\
\hline \multicolumn{3}{|l|}{ Commutating resistance (Ohm) } \\
\hline \multicolumn{3}{|l|}{ Commutating reactance $(\mathrm{Ohm})$} \\
\hline \multicolumn{3}{|l|}{ Measuring Bus } \\
\hline \multicolumn{3}{|l|}{ Transformer ratio (per unit) } \\
\hline \multicolumn{3}{|l|}{ Tap setting (per unit) } \\
\hline \multicolumn{3}{|l|}{ Max tap setting (per unit) } \\
\hline \multicolumn{3}{|l|}{ Mintap setting (per unit) } \\
\hline Tap step (per unti) & & \\
\hline Reactance of CCC( Ohm) & & \\
\hline
\end{tabular}




\subsection{Bi-pole DC Network}

A station of bi-pole converter coupling AC bus with the DC network consists of two converters. Station C1 connected to Kut PS (18406) and C2 to Alameen (16443) are linked by a DC line of length $105 \mathrm{Km}$ with limit of $1400 \mathrm{MW}$ as shown in Figure 6.

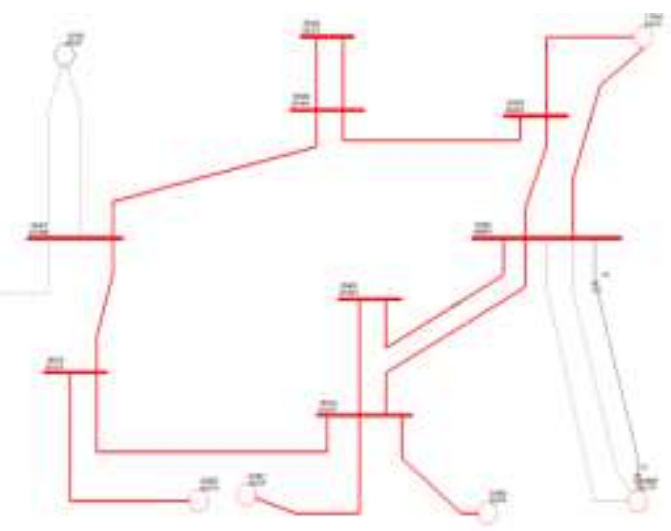

Figure 6. Bipole Connection with Baghdad Ring

Steady state bipolar parameters are shown in Tables 4 and 5 .

Table 4. Bipole DC Line Parameters Value

\begin{tabular}{|c|c|}
\hline Parameter & Value \\
\hline Line Name & \\
\hline Control Mode & \\
\hline Rdc (Ohm) & \\
\hline Rcmp (Ohm) & \\
\hline Delti(per unit) & \\
\hline Setval( Mega Watt) & \\
\hline Vschedule(Kilo volt) & \\
\hline Dcvmin (Kilo volt) & \\
\hline Vcmode(Kilo volt) & \\
\hline CCC Itmax & \\
\hline CCC Accel & \\
\hline
\end{tabular}

Table 5. Converter Parameters Value of Bipole DC Line

\begin{tabular}{|c|l|l|}
\hline Parameter & Rectifier Value & Inverter value \\
\hline Bus Number & & \\
\hline Bus Name & & \\
\hline Max Firing angle $\left(^{\circ}\right)$ & & \\
\hline Min Firing angle $\left(^{\circ}\right)$ & & \\
\hline Bridges in series $^{\circ}$ & & \\
\hline Primary Base (Kilo volt) & & \\
\hline Commutating resistance (Ohm) (Ommutating reactance (Ohm) & & \\
\hline Measuring Bus & & \\
\hline Transformer ratio (per unit) & & \\
\hline Tap setting (per unit) & & \\
\hline Max tap setting (per unit) & & \\
\hline Mintap setting (per unit) & & \\
\hline Tap step (per unti) & & \\
\hline Reactance of CCC( Ohm) & & \\
\hline
\end{tabular}




\section{Results}

It is convenient to compare fault levels before and after high voltage AC/DC coupling to prove the validity of HVDC to limit short circuit levels at sub transient period.

\subsection{Monopole Results}

Fault levels for all busbars in Baghdad region before and after monopolar HVDC were as follows in Table 6 .

Table 6. Baghdad 3 Phase SCL before \& after Monopole Installation between MUSP\& BGS4

\begin{tabular}{|c|c|c|c|}
\hline NO. & Busbar name & $\begin{array}{c}\text { SCL before monopolar } \\
\text { HVDC line installation } \\
\text { (AMP) }\end{array}$ & $\begin{array}{c}\text { SCL with monopolar } \\
\text { HVDC line (AMP) }\end{array}$ \\
\hline 1 & BSMG & 27521.2 & 24626.3 \\
\hline 2 & BGW4 & 17512.7 & 16988.2 \\
\hline 3 & BGS4 & $\mathbf{3 0 7 0 7 . 7}$ & $\mathbf{2 5 7 1 5 . 9}$ \\
\hline 4 & BGE4 & 25891.8 & 24601.35 \\
\hline 5 & BGN4 & 23547.5 & 22634.6 \\
\hline 6 & QDSG & 22368 & 21580.26 \\
\hline 7 & AMN & 31964.9 & 29420.5 \\
\hline 8 & BGC4 & 18740.1 & 18009.39 \\
\hline 9 & MUSP & $\mathbf{2 4 9 2 0 . 2}$ & $\mathbf{1 8 0 5 3 . 4}$ \\
\hline
\end{tabular}

It is clear from Table 2 that SCL of Baghdad South (BGS4) is (30707.7A) and reduced to $(25715.9 \mathrm{~A})$ with variance of $(4991.8 \mathrm{~A})$ when ac line is replaced by mono- polar HVDC line; between BGS4 and MUSP. Likewise MUSP SCL difference of (6866.8 A) is recorded. The chart clarifying the variance stated above shown in Figure 7.

\section{Baghdad Short circuit level before \& after monopole HVDC installation}
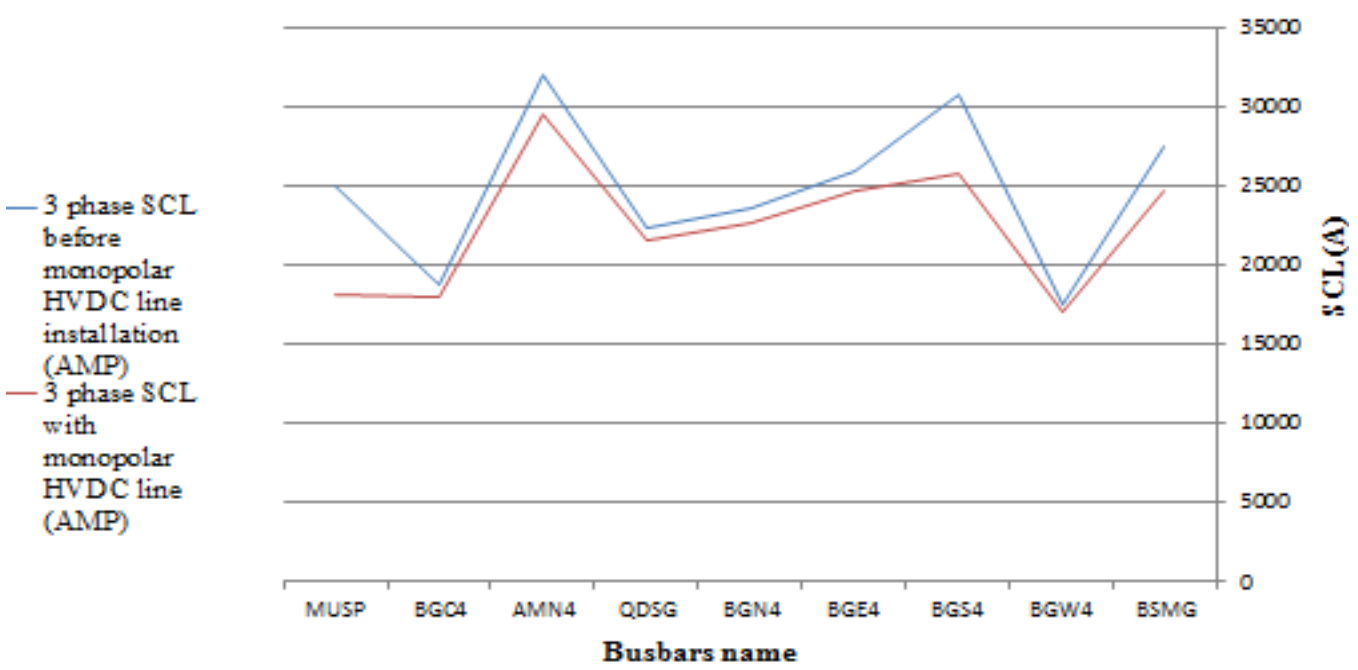

Figure 7. Baghdad Short Circuit Levels with and without Monopole HVDC

\subsection{Bipole Results}

SCLs in Baghdad region formerly and after bipole HVDC is as shown in Table 7. 
Table 7. Baghdad 3 Phase Fault Levels before \& after Bipole Construction between KUTP \& AMN

\begin{tabular}{|c|c|c|c|}
\hline NO. & Busbar name & $\begin{array}{c}\text { SCL before bipolar } \\
\text { HVDC line installation } \\
\text { (AMP) }\end{array}$ & $\begin{array}{c}\text { SCL with bipolar } \\
\text { HVDC line (AMP) }\end{array}$ \\
\hline 1 & BSMG & 27521.2 & 23626.9 \\
\hline 2 & BGW4 & 17512.7 & 16148.1 \\
\hline 3 & BGS4 & 30707.7 & 26346.6 \\
\hline 4 & BGE4 & 25891.8 & 21543.1 \\
\hline 5 & BGN4 & 23547.5 & 20575.4 \\
\hline 6 & QDSG & 22368 & 19782.2 \\
\hline 7 & AMN & $\mathbf{3 1 9 6 4 . 9}$ & $\mathbf{2 3 5 5 0 . 3}$ \\
\hline 8 & BGC4 & 18740.1 & 17240.8 \\
\hline 9 & KUTP & $\mathbf{3 0 5 1 7 . 8}$ & $\mathbf{2 1 8 5 5 . 6}$ \\
\hline
\end{tabular}

It is obvious that Alameen SCL is (31964.9 A) and after installing bi- polar HVDC line; between Alameen and KUTP; it is limited to (23550.3A) with difference of (8414.6 A). Similarly, KUTP SCL difference of (8662.2 A) is registered. The graph illustrating the revealed difference is shown in Figure 8.

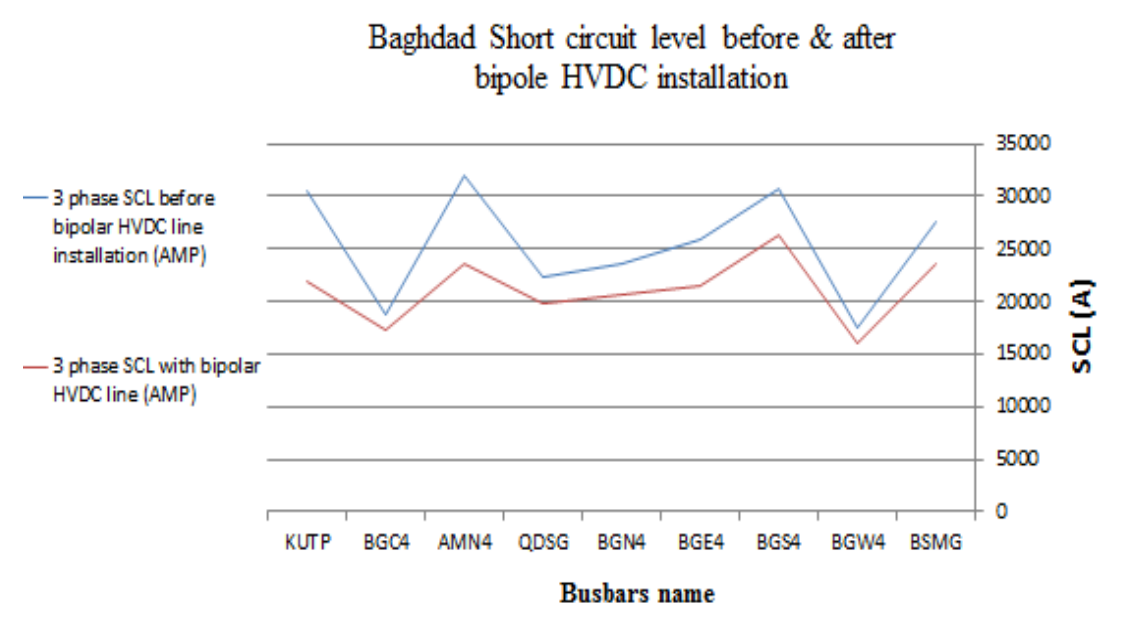

Figure. 8. Baghdad Short Circuit with and without Bipole HVDC

\section{Conclusion}

Applying PSSE tools with suitable sequence, allow engineer to handle an extensive series of investigations of electric power systems design and operation.

HVDC transmission is used for bulk power transmission with lower losses.

For shorter distances HVDC is necessary where other benefits are useful. Most of the usefulness is to clear severe faults and to limit unacceptable high short-circuit currents.

It is obvious from Table 2 and Table 3 that the bipole line was more effective to limit Baghdad SCL for three reasons:

- The DC cable shown in Figure 6 consists of a forward and a return cable laid in parallel.

- KUT PS station's high capacity causes the highest SCL at its busbar; of the Iraqi super grid out of Baghdad region; then coupling this busbar with the bipole DC network is most effective than other busbars.

- The highest SCL in Baghdad region before HVDC was at Alameen (AMN). This bus bar is linked with Kut PS station using bipole net. 
Lastly it is found that bipole affects SCL of the remainder Iraqi grid busbars rather than monopole as shown in Table 8.

Table 8. HVDC Effect on SCL of Iraqi Grid

\begin{tabular}{|c|c|c|c|c|}
\hline NO. & $\begin{array}{c}\text { Busbar } \\
\text { name }\end{array}$ & $\begin{array}{c}\text { SCL before HVDC } \\
\text { line (AMP) }\end{array}$ & $\begin{array}{c}\text { SCL with monopole } \\
\text { HVDC line (AMP) }\end{array}$ & $\begin{array}{c}\text { SCL with bipole } \\
\text { HVDC line (AMP) }\end{array}$ \\
\hline 1 & KRK4 & 8635.4 & 8606 & 8520.7 \\
\hline 2 & DAL4 & 17742.5 & 17153.9 & 15621.1 \\
\hline 3 & KUT4 & 16455.9 & 16401.5 & 14561.4 \\
\hline 4 & KUTP & 30517.8 & 30158.8 & 23873.4 \\
\hline 5 & MUSG & 22110.7 & 16802.3 & 21275.2 \\
\hline 6 & BAB4 & 22301.8 & 18523.7 & 21664.7 \\
\hline 7 & GKHER & 17549.5 & 16291.6 & 17283 \\
\hline 8 & DWANG & 13388 & 13245.8 & 13261.3 \\
\hline 9 & KDS4 & 19706 & 19360.9 & 19398.1 \\
\hline 10 & NSRP & 13642.4 & 13638.1 & 13596.7 \\
\hline 11 & AMR4 & 9304 & 9302 & 9212.9 \\
\hline 12 & 4QRN & 9899.7 & 9899 & 9857.3 \\
\hline 13 & HRTP & 14435.7 & 14435.5 & 14404 \\
\hline 14 & KAZG & 18108.8 & 18108.7 & 18080.7 \\
\hline 15 & RMULG & 16610.7 & 16610.5 & 16593.3 \\
\hline 16 & 4BSR & 15945.7 & 15945.6 & 15930.3 \\
\hline 17 & SHBR & 15455.4 & 15455.3 & 15441.7 \\
\hline 18 & 4NJB & 4833.5 & 4833.5 & 4832.9 \\
\hline
\end{tabular}

\section{References}

[1] M. Eremia, C. C. Liu and A. A. Edris, "Advanced Solutions in Power Systems HVDC, FACTS, and Artificial Intelligence", John Wiley \& Sons, NJ, USA, (2016).

[2] P. Kundur, N. J. Balu and M. G. Lauby, "Power system stability and control", McGraw-Hill Professional, (1994).

[3] N. R. Chaudhuri, B. Chaudhuri, R. Majumder and A. Yazdani, "Multi-Terminal Direct-Current Grids: Modeling, Analysis, and Control”, Hoboken, New Jersey (USA): John Wiley \& Sons Inc., (2014).

[4] M. Nandan, A. Pachori and N. Saxsena, "HVDC Transmission System Using 6- Pulse IGBT", International Journal of Engineering Research and Development, vol. 7, no. 7, (2013) June, pp. 37- 44.

[5] B. Jacobson, P. F. Toledo and G. Asplund, "City Infeed with HVDC Light and Extruded Cables", 16th Conference of the Electric Power Supply Industry, Mumbai, India, (2006) November 6-10.

[6] Z. Xua and C. Zhang, "Case Study: Dynamic Performance of a MTDC Network in Zhoushan City", Applied Energy Symposium and Summit, Elsevier Energy Procedia, vol. 88, (2016), pp. 341-348.

[7] X. Wang, G. Tang, Z. He, X. Wei, H. Pang and X. Xiao, "Modeling and Control of an Isolated Module Multilevel DC/DC Converter for DC Grid", CSEE Journal of Power and Energy Systems, vol. 3, no. 2, (2017) June, pp. 150-159.

[8] T. An, X. Zhou, C. Han, Y. Wu, Z. He, H. Pang and G. Tang, "A DC Grid Benchmark Model for Studies of Interconnection of Power Systems", CSEE Journal of Power and Energy Systems, vol. 1, no. 4, (2015) December, pp. 101-109.

[9] P. Ye, Y. Sui, Y. Yuan, X. Li and J. Tao, "Transient Stability Analysis of Hu-Liao HVDC and AC Parallel Transmission System", Smart Grid and Renewable Energy, vol. 1, no. 2, (2010), pp. 74-80.

[10] D. Zhang, X. Jin, B. Zhou, H. Su, Y. Chen and L. Zhu, "A Study on HVDC User- Defined Modeling in PSS/E", fifth International Conference on Electric Utility Deregulation and Restructuring and Power Technologies, Changsha, China, (2015) November 26-29, pp. 386-391.

[11] D. H. Kwon, H. J. Moon, R. G. Kim, C. G. Kim and S. I. Moon, "Modeling of CIGRE Benchmark HVDC System Using PSS/E Compared with PSCAD", Proceedings of the International Youth Conference on Energy, Pisa, Italy, (2015).

[12] O. M. Fahmy, "Analysis of Existing Power Flow Case for South Operating Area Network", IEEE conference in Smart Grid (SASG), Saudi Arabia, (2016) December.

[13] PSS/E 31.0, "Program Application Guid", Volume I, Siemens P.T.I., Schenectady, NY, USA, (2007) December. 
International Journal of Control and Automation

Vol. 11, No. 5 (2018)

[14] S. Hwang, J. Lee and G. Jang, "HVDC-System-Interaction Assessment through Line-Flow ChangeDistribution Factor and Transient-Stability Analysis at Planning Stage", Energies Journal, (2016) September.

[15] Republic of Iraq, Ministry of Electricity, Planning and Studies Office, (2017). 